\title{
Fuzzy Controller for Automatic Steering in Heavy Vehicle Semi-Trailers
}

\section{Controlador difuso para conducción automática de vehículos pesados tipo semi-trailer}

\author{
Bortoni-Anzures L. \\ Universidad Autónoma de Querétaro \\ Facultad de Ingeniería \\ E-mail:bortoni@nzures.com \\ Gómez-Meléndez D. \\ Universidad Autónoma de Querétaro \\ Facultad de Ingeniería \\ E-mail:domag5@hotmail.com
}

\author{
Herrera-Ruíz G. \\ Universidad Autónoma de Querétaro \\ Facultad de Ingeniería \\ E-mail:gherrera@uaq.mx \\ Martínez-Madrid M. \\ Instituto Mexicano del Transporte \\ Tamaulipas, México \\ E-mail:Martinez@imt.mx
}

Information on the article: received: November 2007, reevaluated: April 2008, accepted: February 2012

\begin{abstract}
Trucks with semi-trailers are widely used for transportation of goods due their low operation cost, but inherent to these vehicles are some problems such as a poor maneuverability. To minimize the effects of this disadvantage, among other solutions, the incorporation of steerable axles in the semitrailers has been proposed. This paper presents a steering equation, and a fuzzy-logic controller for a semi-trailer automatic forced-steering system to minimize the off-tracking and the total swept path width, resulting in an improvement of vehicle's maneuverability at low speeds. To accomplish this, the suggested control algorithm considers the articulation angle and parameters such as vehicle speed and direction. The system was tested on an instrumented experimental semi-trailer during various predetermined test maneuvers.
\end{abstract}

\section{Keywords:}

- Semi-trailer

- automatic steering

- fuzzy control

- maneuverability 


\section{Resumen}

Los vehículos tractor-semirremolque se usan ampliamente para el transporte de mercancías debido su bajo costo de operación, pero hay algunos problemas inherentes a estos vehículos, como una pobre maniobrabilidad. Para minimizar los efectos de esta desventaja, entre otras soluciones, se ha propuesto la incorporación de ejes direccionales en los semirremolques. En este trabajo se presenta una ecuación de dirección y un control mediante lógica difusa para un sistema automático de dirección forzada para semirremolque para minimizar el despiste y el ancho de vía, mejorando la maniobrabilidad del vehículo a velocidades bajas. El algoritmo de control sugerido considera el ángulo de la articulación y parámetros como velocidad del vehículo y su dirección. El sistema se probó en un semirremolque experimental instrumentado durante varias maniobras experimentales predeterminadas.

\section{Introduction}

Articulated vehicles have proven their economic profitability, but as the number of these vehicles grows, it becomes evident that there is a substantial need to improve their handling control performance.

Different approaches have been taken into consideration; one important and promising is related to trajectory matching and lateral control of these heavy vehicles. In this line of work the objective is, in general, to make the articulated vehicles able to follow a secure and efficient path (Bolzern and Locatelli, 2001; El-Gindy, 1978; Hingwe et al., 2000; Sampei et al., 1995 and Tsao et al., 2006), are a few of researchers who specialize in trajectory matching.

The biggest project in this area is the California Partners for Advanced Transit and Highways (California Paths) (Hingwe et al., 2000) where numerous groups of government, public and private institutions are involved in the development of automated highway systems (AHS).

A different approach is to propose design modifications or the implementation of mechanical components that improve overall vehicular maneuverability performance. Steerable axles on semi-trailers are an option to, not only improve maneuverability, but also reduce risk of accidents and decrease fuel consumption and tire wear. Further, it may also minimize hazards and damage to roadway infrastructures. Several mechanical configurations have been tested via computer simulation (Sankar et al., 1991), yet few of them are already used as prototypes or are in early commercial stages.

Those mechanisms represent significant benefits for vehicles, but they still need to be improved since some stability problems have been raised. Inside the group of steering axles of a semitrailer, the command-steer system is the most efficient option (Jujnovich and Cebon, 2002).
In 2000 an Australian company, Gayat Pty. Ltd. (Prem and Ramsay, 2001) and in 2005 the Cambridge Vehicle Dynamics Consortium (Cambridge University) (Neads, 2006) presented full scale prototypes of semitrailers with command steer axles systems, each of them is part of the evolution of this technology.

Moreover, results from the tests carried out for this paper present work on an actual experimental semitrailer. These results also show a control equation with a proposed method of employment for a system of control based on fuzzy-logic that could further advance in command steering technology.

\section{Materials and methods}

An experimental semi-trailer was made in order to obtain a better understanding of the articulated vehicles maneuverability performance and the most significant characteristics affecting it.

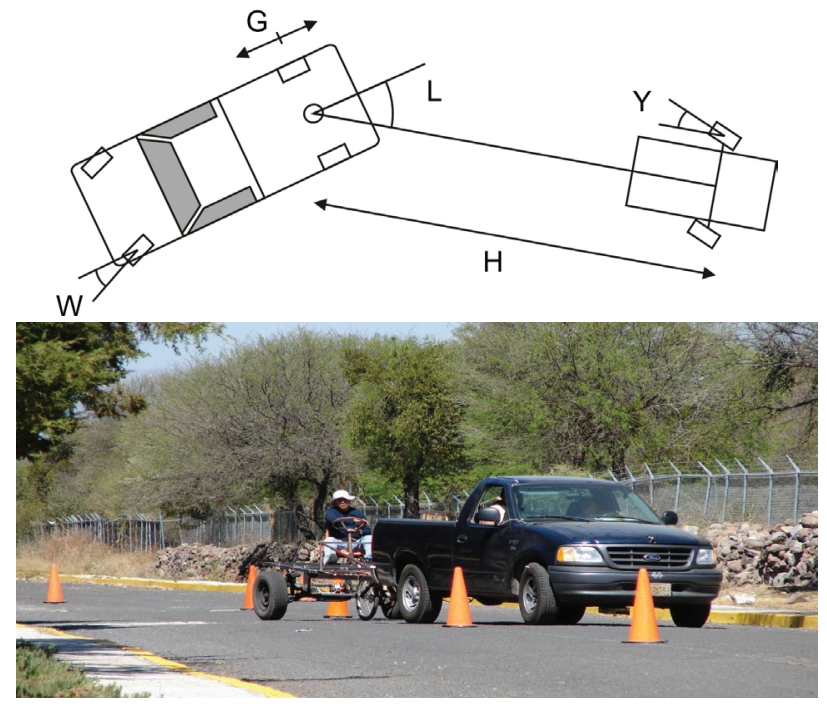

Figure 1. Experimental vehicle 
Pulled by a pickup truck, this semi-trailer which is shown in Figure 1 incorporates several configurable characteristics such as the location on the fifth wheel (G) in front, on top or in the back from the traction axle. The length of the semi-trailer $(\mathrm{H})$ and an axle in the semi-trailer that is configurable as fixed or steerable, allowing the testing of different control schemes.

\section{Instrumentation}

To track the geometric behavior of the vehicle, a GPS receiver was installed on top of the fifth wheel, and angular transducers in the steering wheels of the truck, in the hitch and in the steering wheels of the semi-trailer. This procedure is clearly explained in (Bortoni et al., 2007).

Also accurate yaw rate sensors and lateral accelerometers were placed in the chassis of the truck and the semi-trailer. Finally a mini camera was installed in the front of the truck pointed toward the ground to guide the driver during specific maneuvers (Figure 2).

The signals were monitored by two portable computers. The sample rate was established in 50 samples per second per channel. This sampling frequency was considered high enough to have a detailed time history of the measurements.

\section{Handling performance}

Handling performance is the result of a vehicle's steering inputs determined by the vehicle weights, dimensions, and mechanical properties of the tires, suspension, vehicle frames, and weight distribution among the axles (Sampson, 2000).

Consequently, a number of performance measures can be compiled to assess the maneuverability performance of the vehicles, particularly with regard to articulated trucks. This study considers the performance measures related to geometrical requirements, as:

\section{Off-tracking}

Whenever a vehicle with more than one axle turns, rear wheels fail to follow the path of front wheels precisely. Off tracking measures the maximum distance between the paths of the steering axle and the axle of the most rearward wheels (Battelle Team, 1995).

\section{Swept path width}

Jujnovich and Cebon (2002) describe the "swept path width" as the maximum width of the swept trajectory in a small radius turn. Figure 3 shows both, the off-trac-
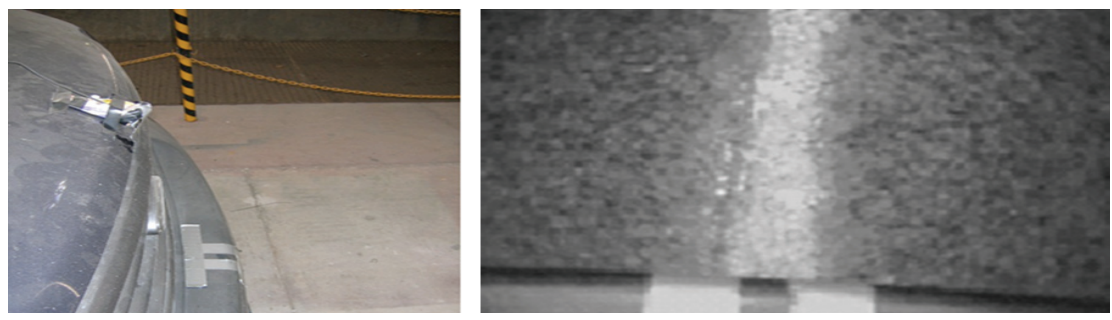

Figure 2. Video camera and video camera view at marks at the front of the truck

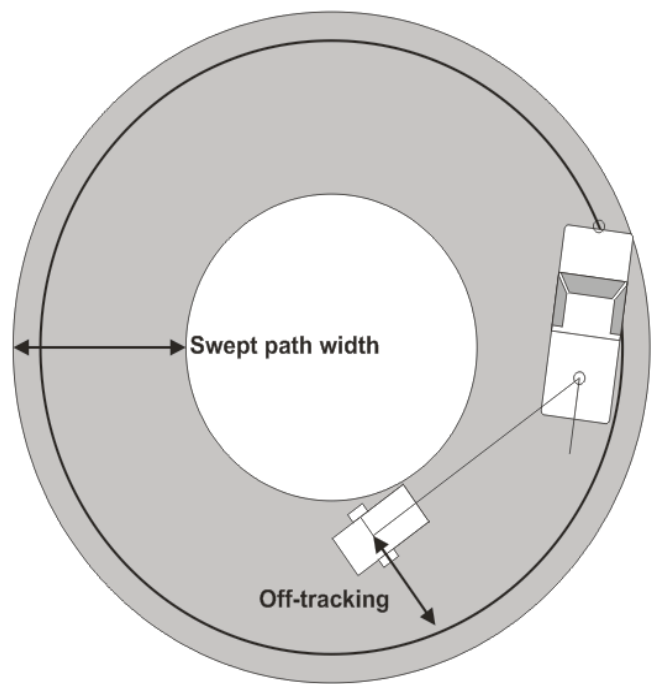

Figure 3. Off-tracking and swept path width during a stationary turn 
king and swept path width measurements during circular constant radius turns, also called stationary turns.

\section{Test maneuvers}

For testing, three different maneuvers were considered: two related to a predetermined defined following path and one slalom type. The first two consisted of a stationary turn and a $90^{\circ}$ transient turn, performed at a very low velocity.

Circular and transient curve paths were traced on the pavement surfaces which were to be followed by the truck to facilitate the path following an 8,9.5 and $11.25 \mathrm{~m}$. radius, the stationary turn like the illustration in Figure 3 and transient turn in Figures 4 and 5.

Figure 4 shows the typical maneuverability performance of an articulated vehicle. $f$ stands for the angle of the front axle, the steering axle on the truck, and a for the articulation angle.

In the case when the $9.5 \mathrm{~m}$ maneuver was made, the results observed demonstrated that the angle of the articulation reached $40^{\circ}$ which means an off-tracking of $2.95 \mathrm{~m}$ and a swept path width of $4.6 \mathrm{~m}$.

When the semi-trailer axle is set to command steer as seen in Figure 5, it was found that the maneuver results in a maximum articulation angle of barely $22^{\circ}$, which is an improvement of approximately $50 \%$, therefore resulting in a negative off-tracking and a swept path width that equals that of the width of the vehicle.

The line $\mathbf{r}$ represents the angle of the semi-trailer axle, and as Figure 5 shows, the driver in the semi-trailer performs a momentary opposite turn to get better alignment with the truck. When it leaves the transient part of the maneuver, in this case a $20^{\circ}$ turn, the semitrailer axle was applied.

Besides the different radius, these maneuvers were performed from the left and from the right, under different vehicular configurations as the longitude of the semi-trailer and the fifth wheel location.

The slalom type maneuver consists of a series of directional changes around vial cones that were placed 10 meters apart on a street that was $7 \mathrm{~m}$ wide while maintaining a constant speed of $8 \mathrm{~km} / \mathrm{h}$. Figure 1 shows the vehicle during the slalom maneuver.

In these maneuvers there is not a defined trajectory, so the driver relies on his perception and expertise to deal with the obstacles. In this case the way to evaluate the maneuver is directly related to the lateral speed of the truck in contrast with the one on the semi-trailer.
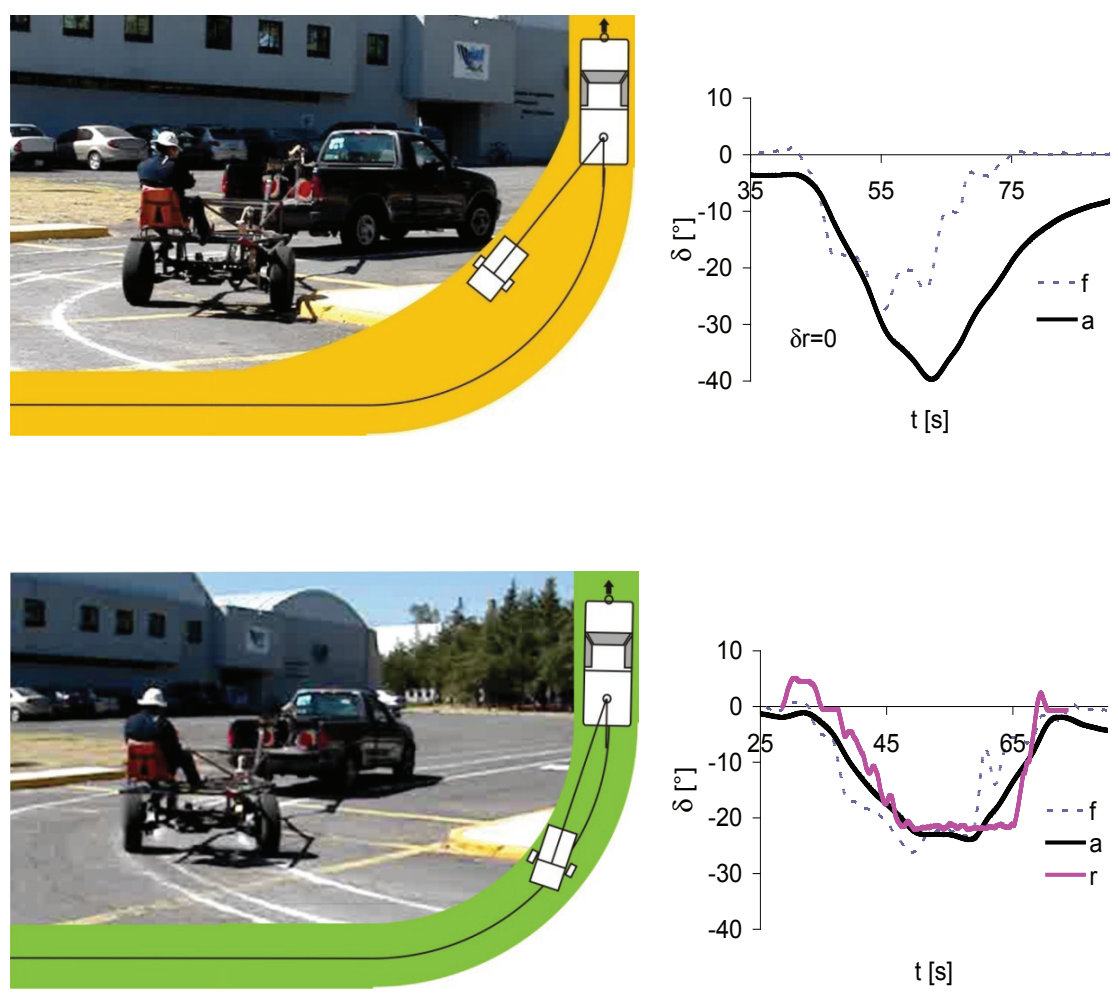

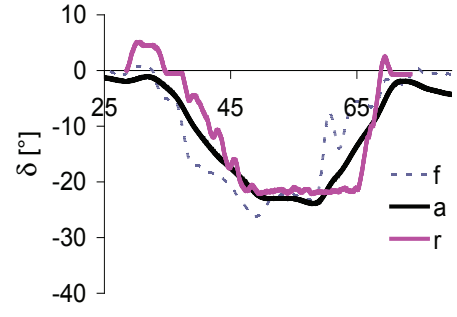

$\mathrm{t}[\mathrm{s}]$
Figure 4. Transient turn with fixed semitrailer axle

Figure 5. Transient turn with command steering semi-trailer axle 
In Figure 6A, the lateral speed of the truck is almost twice that of the semi-trailer. This means that the truck is under high demand for the vehicle to avoid obstacles. On the other hand, in Figure 6B when the command steering was activated the speed of the truck and the semi-trailer, is almost the same, requiring less lateral space.

The difference in magnitude in the left verses the right turn corresponds to the perception of the driver. Note: It is easier to follow the obstacle and the edge on the driver's side. Also, in the pictures can be noticed de difference in road space demand, with the fixed axle semi-trailer, the vehicle use the full wide of the road, and even then it fails to deal with all of the obstacles. While the command steer semi-trailer succeed all obstacles occupying less space.

There is a significant amount of literature regarding studies comparing the behavior between fixed axles and steering command ones using simulation models. In most cases it was concluded that by incorporating steering axles important benefits can be obtained such as improving handling capabilities of the vehicle and reduction of tire friction demand (Jujnovich and Cebon, 2002; Billing and Patten, 2003).
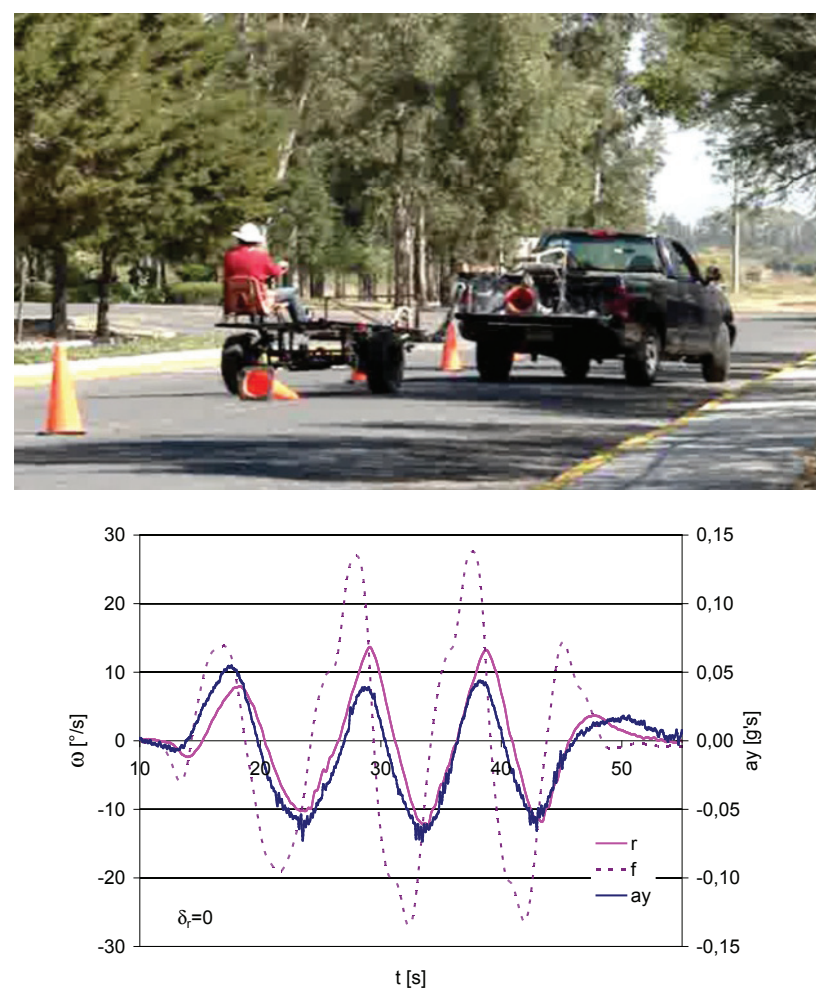

a)

Figure 6. Shows yaw rates and semi-trailer's axle lateral acceleration history, a) is the fixed semi-trailer axle, while b) is the steerable semi-trailer's axle
Test results using an experimental vehicle confirm this, but it also extends the scope of testing beyond most simulation results and illustrates some aspects of the driver's perception on the experimental assessments which in turn affects the maneuver performance.

\section{Control equation}

During previous tests on full scale vehicles (Figure 7) and from the Ackerman equations, the angle in the semi-trailer axle that would minimize the off-tracking for each radios turn were geometrically calculated This defines the general behavior required for the specific semi-trailer dimensional configuration.

The same dimensional characteristics were considered in the construction of the experimental semi-trailer, in order to fine tune the control equation and to later experiment with the width the parameters in the algorithm of control.

After this, by combining the dimensional characteristics of the semi-trailer with the Ackerman equations, an evaluation computer program was set up to track the off-tracking results during the test maneuvers pe-
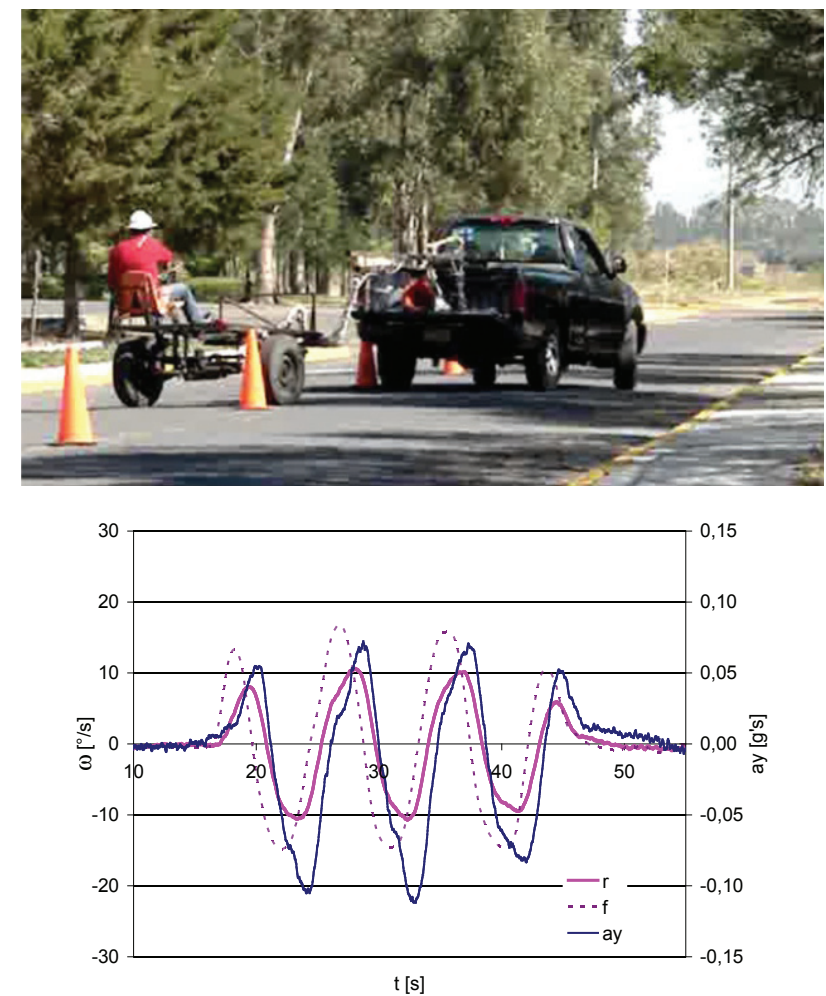

b) 
riod and by using interpolation regression techniques, a control equation was defined (Eq. 1 and 2, Figure 8).

Figure 8 shows the final curve of response in the command steering axle of the semi-trailer in relation to the articulation angle. The resulting equation of control was defined as:

$\mathrm{X}=\exp (-1.370004 \mathrm{G}+0.099728 \mathrm{H}+0.833331 \mathrm{~J}-1.102983)$

where

$G=5$ th wheel to rear tractor axle distance

$\mathrm{H}=5$ th wheel pin to last trailer axle distance
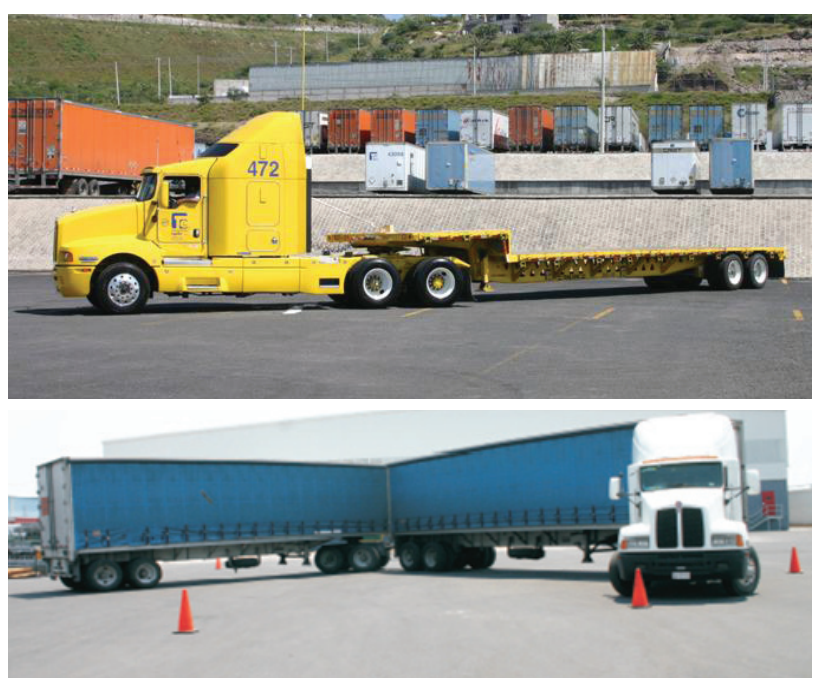

Figure 7. Test vehicles used in the definition of the control equation

\section{Semi-trailer steering angle}

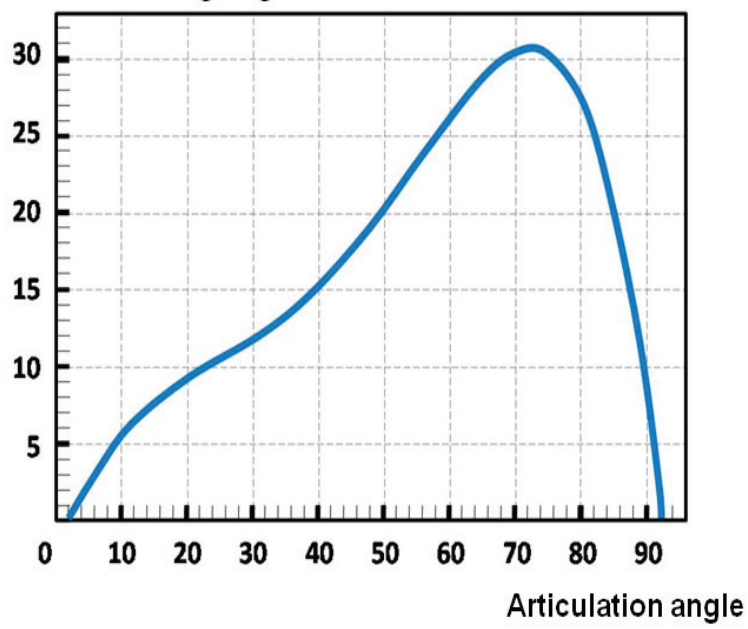

Figure 8. Articulation angle vs. steering angle on semi-trailer axle to minimize off-tracking (values in degrees)
$\mathrm{J}$ = spacing between trailer axles

Note: G, H and L are illustrated in figure 1.

$\mathrm{Y}=-3.36 \mathrm{E}^{-07} \mathrm{~L} X^{5}+9.3698 \mathrm{E}^{-06} \mathrm{~L} X^{4}+1.4672 \mathrm{E}^{-03} \mathrm{LX}^{3}-7.2697 \mathrm{E}^{-02}$

$\mathrm{LX}^{2}+1.5551 \mathrm{LX}-1.9183$

where

$\mathrm{L}=$ articulation angle

Factor $\mathrm{X}$ in equation 1 refers to the dimensional specification of the semi-trailer G, H, L and $\mathrm{Y}$ are all illustrated in Figure 1. In equation 2, $\mathrm{L}$ is the articulation on the fifth wheel measured in degrees and $Y$ corresponds to the angle required by the steering axle of the semi-trailer to minimize off-tracking.

\section{Fuzzy-logic control}

As well as prior prototypes developed in Australia and England, endow of steering control in the semi-trailer improves maneuverability, but also increases the risk of vehicular instability.

During the testing, there was some experimentation with certain parameters that could minimize potential stability loss, for example, consider vehicle's speed. These defined behaviors would apply during maneuvers at lower vehicular speeds and, as speed is increased, the system's angle of the steering axle of the semi-trailer should decrease proportionally, to the point were the system will be set to null response at speeds higher than $60 \mathrm{Km} / \mathrm{h}$ (Figure 9).

Also the vehicle's speed has an impact on the response speed of the system which means that at very low vehicular speeds, the system will promptly execute angular adjustments, but as vehicle speed increases, these adjustments to the steering wheels will be performed more slowly.

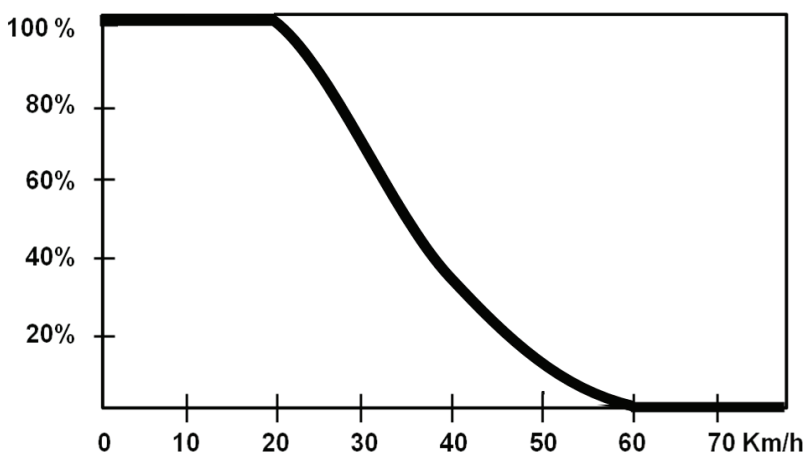

Figure 9. Response in the system based in vehicular velocity 
Another parameter to be considered is the marginal angular changes. This consists of a time delay in the response of the system to changes in the articulation angle in order to prevent undesired oscillations that could occur during fast angle variations for example when the vehicle encounters a road or speed bump. If the angle variation doesn't remain for at least two seconds, the system should ignore it.

Finally, all this considerations will be affected by the weight carried in the semitrailer, due this and the multivariable and non-linear nature of the system, an intelligent control technique was required, taking into consideration fuzzy logic which is part of artificial intelligence techniques and is an attractive and well-established approach to solving control problems (Lee, 1990).

Fuzzy logic provides a methodology to represent, manipulate and implement expert heuristic knowledge for controlling a system. Also, with a fuzzy controller, robustness and low cost are inherent to each development (Passino, 1998).

The set of fuzzy rules to develop the control system for each variable was obtained and fine tuned during the test rides of the experimental semi-trailer.

Figure 10 shows the example of two membership groups: a) articulation angle, with six linguistic varia- bles to represent all the angle values: Zero, 4 to 20, 20 to 50,50 to 74,74 to 82 and 82 to 90 ; as an example 4 to 20 means that the value is between 4 and 20 degrees, considering zero degrees when the tractor and the semitrailer are aligned or in angles between 0 and $4^{\circ}$, and b) vehicular speed, with four linguistic variables: low, middle, middle-high, and high, both articulation angle and vehicular speed will be used to feed the fuzzy angle estimator in order to calculate the angle of the steering axles.

This calculated angle is then compared with the current steering wheels angle to determine the corrections that should be applied to the steering mechanism (block diagram illustrated in Figure 11).

The corrections made by the fuzzy mechanical control are then compared cyclically retro-feeding the system to avoid over-steer. Figure 12 shows the membership functions group belonging to the error variable of the fuzzy control module, with "low", "ok" and "high" as linguistic variables, to deal with the vehicular specific characteristics, such as: deformations caused by the lateral forces, deformations caused by the longitudinal forces, deformations caused by the auto-alignment forces, semi-trailer length, rigidity of the steering mechanism and drift rigidity of the tires.
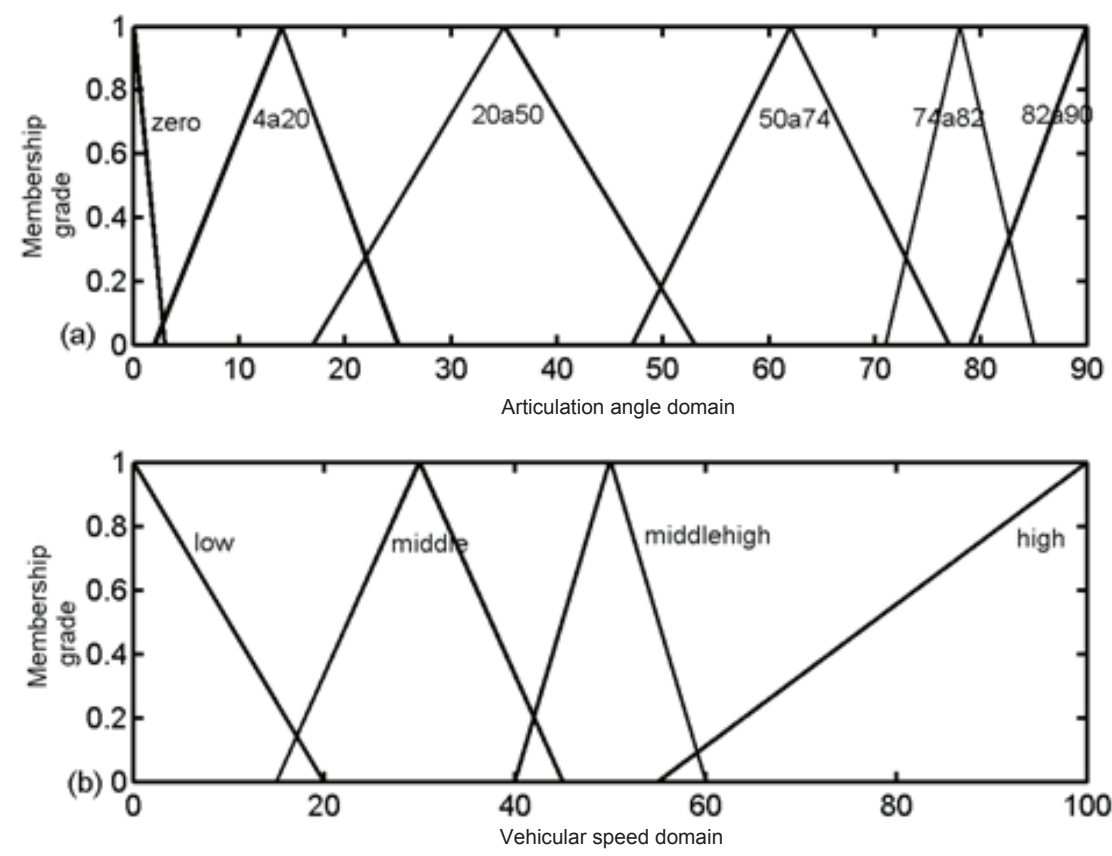

Figure 10. Membership functions: a) articulation angle and b) vehicle speed 


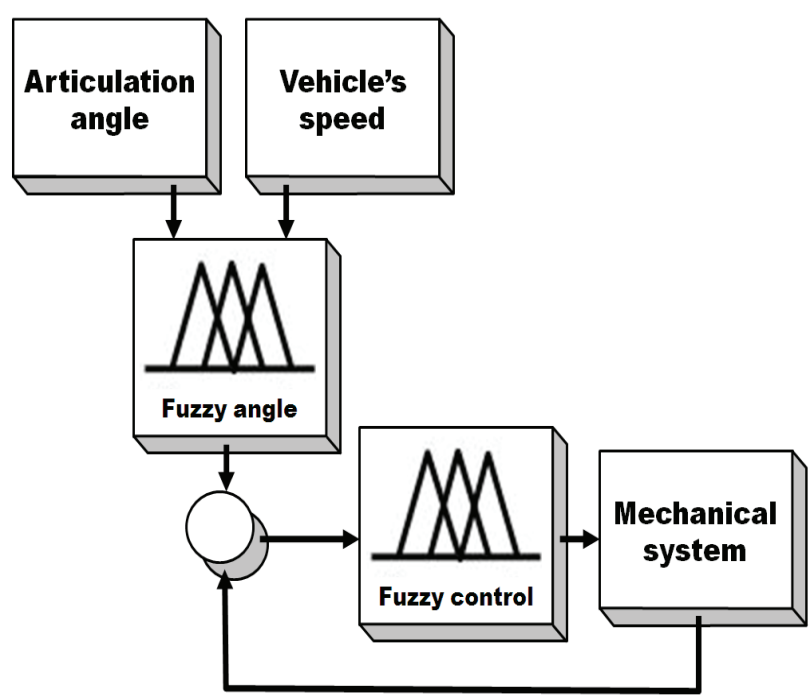

Figure 11. Fuzzy-controller block diagram

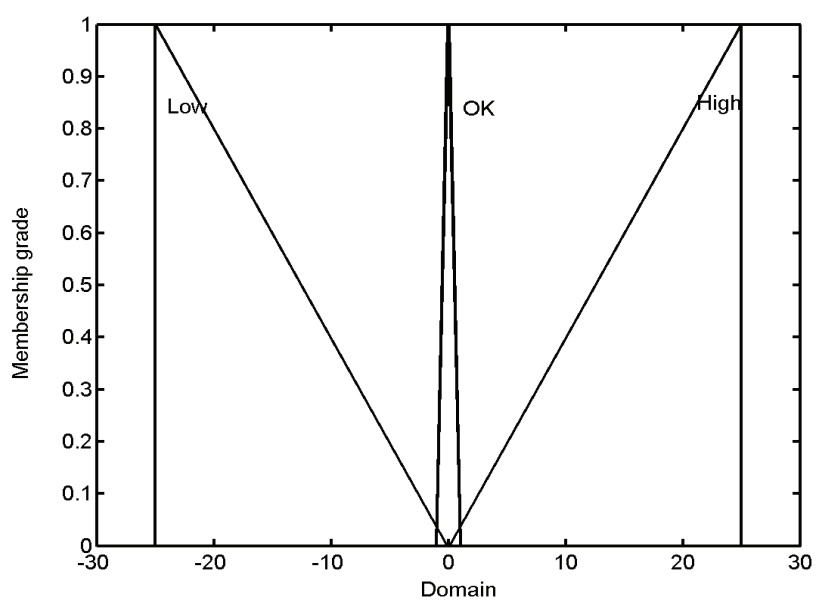

Figure 12. Error membership function

\section{Conclusion}

Heavy articulated vehicles are used world-wide, as one of the most feasible solutions for freight. Due to the length dimensions and weight they encounter poor maneuverability.

The handling of this kind of such vehicles can be greatly improved by using steering axles in the semitrailer to reduce the required road surface necessary to perform a turn maneuver placing less demand on lateral tire efforts and consequently decreasing the risk of loosing vehicular directional control, not to mention the reduction of tire wear and scrub. Likewise, by reducing lateral tire friction, the damage to road infrastructures will be minimized.
Fuzzy control represents a useful tool in dealing with non-linear systems. The controller approach presented in this paper is an alternative to solve some of the problems related to command steering in semi-trailers without detriment to the improved maneuverability provided from this type of systems.

The growing demand in freight transportation systems will soon require more efficient vehicles that are more secure and intelligent, as well as environmentally friendly. IE: Will not cause damage to the road infrastructures. In the years to come these varied demands will lead to the implementation of new technologies and designs.

\section{Acknowledgments}

This research was sponsored by Consejo Nacional de Ciencia, Tecnología, Universidad Autónoma de Querétaro and Instituto Mexicano del Transporte.

\section{References}

Battelle Team. Comprehensive Truck Size and Weight Study, Federal Highway Administration, US Department of Transportation, 1995.

Billing J. and Patten J. Performance of Infrastructure-Friendly Vehicles, Center for Surface Transportation Technology, National Research Council of Canada, Technical Report CSTTHVC-TR-058. Canadá, 2003.

Bolzern P. and Locatelli A. A Comparative Study of Different Solutions to the Path-tracking Problem of an Articulated Vehicle, Politecnico di Milano, on: IEEE International Conference on Control Applications, UK, 2002.

Bortoni L., Martínez M., Herrera G., Castañeda R. On-Board Instrumentation to Assess Articulated Vehicle Maneuverability, included in Commercial Vehicle Advancements in Braking, Steering Systems and Vehicle Stability Control Affects, USA, 2007.

El-Gindy. A Comparison of Various Computer Simulation Models for Predicting the Directional Responses of Articulated Vehicles, Vehicle System Dynamics, Canada 1987, pp. 249-268.

Hingwe P., Wang J., Tai M., Tomizuka M. Lateral Control of Heavy Duty Vehicles for Automated Highway System: Experimental Study on a Tractor Semi-Trailer, University of California, Berkeley, 2000.

Jujnovich B. and Cebon D. Comparative Performance of SemiTrailer Steering Systems, on: 7th International Symposium on Heavy Vehicle Weights and Dimensions, University of Cambridge, UK [on line], 2002. Available: www.cvdc.org

Lee C.C. Fuzzy Logic in Control Systems: Fuzzy Logic Controller, parts I and II. Transactions on Systems, Man, and Cybernetics, volume 20, 1990: 404-432. 
Neads S. Path Following in Articulated Vehicle, Antony Best Dynamics, UK, 2006.

Passino M. Fuzzy Control. Department of Electrical Engineering, Addison-Wesley, Longman Inc, California, USA, 1998.

Prem H. and Ramsay E. Performance Evaluation of the Trackaxle SelfSteering System, RTDynamics, Australia, 2001.

Sampei M., Tamura T., Kobayashi T., Shibui N. Arbitrary Path Tracking Control of Articulte Vehicules Using Nonlinear Control Theory. IEEE Transactions on Control Systems Technology, volume 3 (issue 1), 1995.

Sampson D. Active Roll Control of Articulated Heavy Vehicles, Churchill College, University of Cambridge, UK, 2000.

Sankar S., Rakheja S., Piche A. Directional Dynamics of a TractorSemitrailer with Self- and Forced-Steering Axles, Concave Research Centre, Concordia University, Canada, 1991.

Tsao J., Dessouky Y., Rangavajhula K., Zeta J., Zhou L. Automatic Steering For Conventional Truck Trailers, San Jose State University, California PATH Research Report, USA, 2006.

\section{Citation for this article: \\ Chicago citation style}

Bortoni-Anzures, Liborio, Domingo Gómez-Meléndez, Gilberto Herrera-Ruíz, Miguel Martínez-Madrid. Fuzzy Controller for Automatic Steering in Heavy Vehicle Semi-Trailers. Ingeniería Investigación y Tecnología XIV, 01 (2013): 1-9.

\section{ISO 690 citation style}

Bortoni-Anzures L., Gómez-Meléndez D., Herrera-Ruíz G., Martínez-Madrid M. Fuzzy Controller for Automatic Steering in Heavy Vehicle Semi-Trailers. Ingeniería Investigación y Tecnología, volume XIV (issue 1), January-March 2013: 1-9.

\footnotetext{
About the authors

Liborio Bortoni-Anzures. Bsc in Industrial Engineer, Instituto Tecnologico de Cd. Victoria, Mexico; Masters degree in Mechanical Engineering, Universidad Politecnica de Madrid, Spain; Doctor in Engineering, University of Queretaro, México. Member of research group of Mexico Institute of Transportation; lecturer on Physics and Electrocnics in different universities of Mexico. Project development leader on systems and production control, as well as research on intelligent vehicles at Chrysler de Mexico.

Domingo Gómez-Meléndez. Mechanical Enegineer, Universidad de Santander, Spain; Masters on Engineering and Control and Doctor in Engineering from University of Queretaro, Mexico. Currently working on fussy control for irrigation and climate control in green house of University of Queretaro.

Gilberto Herrera-Ruíz. Electronic systems Engineer and Masters degree in Electronics Engineering, Institute of Technology of Monterrey, Mexico. Doctor in Automation Systems, Technology University of Budapest, Hungary. Post Doc in Industrial Automation and Modern Manufacturing Techniques, Institute of Mechanical Engineering, Tsukuba, Japan. Currenty director of the University of Queretaro.

Miguel Martínez-Madrid. BsC in Metallurgy Engineer, National University of Mexico. $\mathrm{PhD}$ in Metallurgy and Materials Science, University of Cambridge, UK. Member of the national researchers system of Mexico, Number Member of Mexican Academy of Engineering; Technical consultant of different high technology companies in Mexico and USA; currently head of research group named Structural Integrity and Vehicle Dynamics at Mexico's Institute of Transportation.
} 